\title{
PEMANFAATAN MEDIA BUSUU ONLINE UNTUK MENINGKATKAN KOMPETENSI GURU BAHASA INGGRIS SD TERHADAP KEMAMPUAN KOSAKATA (VOCABULARY) DAN BERBICARA (SPEAKING)
}

\author{
Widi Winarso ${ }^{1}$, Ferawaty Puspitorini ${ }^{2}$, Kardinah Indrianna ${ }^{3}$, Mulyadi ${ }^{4}$, Rorim Panday ${ }^{5}$, Tutiek \\ Yoganingsih 6 \\ ${ }^{1,3,5}$ Prodi Manajemen, Fakultas Ekonomi dan Bisnis, Universitas Bhayangkara Jakarta \\ Raya, Bekasi. \\ 2,4,6Prodi Akuntansi, Fakultas Ekonomi dan Bisnis Universitas Bhayangkara Jakarta Raya, \\ Bekasi.
}

E-mail: bintang.narpati@gmail.com ${ }^{1}$, ferawaty.puspitorini@dsn.ubharajaya.ac.id², tya@ubharajaya.ac.id ${ }^{3}$, mulyadi@dsn.ubharajaya.ac.id ${ }^{4}$, indripan@gmail.com ${ }^{5}$, tutiekyn@gmail.com ${ }^{6}$

Penulis untuk Korespondensi/E-mail: ferawaty.puspitorini@dsn.ubharajaya.ac.id

\begin{abstract}
Abstrak
Tujuan penelitian ini adalah untuk mengingkatan kompetensi kosakata dan berbicara bahasa Inggris guru-guru SD dengan memanfaatkan media busuu online. Metode yang digunakan dalam penelitian ini adalah metode deskriptif. Sampel dalam penelitian ini adalah guru-guru SD Yasporbi Jakarta. Peneliti memberikan soal kosakata dan berbicara sebelum perlakuan menggunakan media busuu online dalam bentuk pilihan ganda, dan soal kosakata dan berbicara setelah perlakuan menggunakan media busuu online. Hasil dari penelitian ini menunjukkan adanya peningkatan keterampilan menyimak yang ditunjukkan dengan peningkatan nilai evaluasi (post-test).
\end{abstract}

Kata Kunci : Media Online, Busuu, Kosakata, Berbicara, Bahasa Inggris

\begin{abstract}
The purpose of this research is to improve the competence of English language vocabulary of junior English teachers by utilizing the online busuu media. The method used in this research is descriptive method. The sample in this research is teachers of SD Yasporbi Jakarta. Researchers provide vocabulary and speaking test before treatment (pre-test) using online busuu media in the form of multiple choice, and vocabulary and speaking test after treatment (post-test) using online busuu media. The results of this study indicate an increase in listening skills as indicated by an increase in the value of post-test.
\end{abstract}

Keywords: Online Media, Busuu, Vocabulary, Speaking, English

\section{PENDAHULUAN}

Bahasa merupakan alat komunikasi, oleh karena itu pembelajaran dan penguasaan bahasa sangat penting. Di Indonesia, bahasa Inggris merupakan bahasa asing pertama yang diajarkan di sekolah formal mulai dari tingkat Sekolah Dasar sampai Perguruan Tinggi. Maka dari itu, penting bagi masyarakat Indonesia untuk mempelajarai bahasa Inggris untuk dapat berkomunikasi di dunia internasional.

Tujuan pembelajaran bahasa adalah dapat berkomunikasi baik lisan maupun tertulis dengan bahasa yang dipelajari. Ada empat ketrampilan yang harus dikuasai saat mempelajari bahasa Inggris, adapun ketrampilan tersebut adalah menyimak (listening), berbicara (speaking), membaca (reading), dan menulis (writing). Ketrampilan 
berbahasa ini berkaitan antara satu dengan yang lain dan juga untuk mencapai tujuan belajar bahasa juga pembelajar idealnya mempelajari komponen bahasa, seperti tatabahasa (structure), kosakata (vocabulary), pengucapan (prunounciation).

Dilihat dari tujuan utama pembelajaran bahasa yang sudah dikemukakan di atas, tujuan pembelajaran bahasa Inggris di Indonesia adalah agar siswa dapat mengerti dan paham bacaan (reading comprehension) ataupun komunikasi secara lisan dan tertulis (oral and written communication). Berdasarkan pengamatan penulis, pengajaran bahasa Inggris di Sekolah Dasar (SD) mempunyai fokus pada pengenalan dan penambahan kosakata, pemahaman teks sederhana dan pemberian respon pada percakapan sederhana. Oleh karena itu, guru Sekolah Dasar ( SD ), yang mulai mengajar mata pelajaran bahasa Ingris secara khusus, diharapkan mempunyai kemampuan dasar bahasa Inggris yang dapat diajarkan kepada siswa.

Tidak dapat dipungkiri bahwa dunia pendidikan terpengaruh oleh kemajuan teknologi. Banyak maanfaat dari teknologi yang dapat digunakan dalam dunia pendidikan, sebagai contoh dengan mudahnya akses internet guru ataupun tenaga pengajar dapat dengan mudah mencari materi pendukung pengajaran melalui internet, materi tersebut dapat berupa artikel online, softcopy buku, video maupun audio pembelajaran. Sebagai media pendukung pengajaran banyak sekali hal yang dapat dilakukan dengan memanfaatkan teknologi. Tidak hanya dalam proses untuk media pendukung, saat ini banyak pula yang dapat dimanfaatkan secara langsung sebagai media pengajaran, sebagai contoh dengan adanya webblogs dapat membantu guru menjelaskan materi kepada siswa secara online. Banyak pula software yang dapat diunduh secara gratis untuk mendukung kegiatan belajar mengajar.

Ketika para guru SD dihadapkan dengan latihan tes kosakata (vocabulary), mereka sering kali mengalami kendala dalam hal waktu, tempat dan tutor. Waktu yang sangat terbatas untuk para guru untuk melatih kemampuan bahasa Inggris mereka menjadikan mereka malas untuk berlatih. Padahal latihan pada pembelajaran bahasa sangatlah penting.

Kendala seperti ini sekarang tidaklah menjadi sebuah masalah besar. Karena sekarang, dengan internet dapat memudahkan para praktisi pendidikan untuk berlatih kemampuan kosakata (vocabulary) kapanpun dan dimanapun. Media busuu online dapat diakses dimanapun untuk meningkatkan kompetensi bahasa Inggris. Dengan adanya media busuu ini dapat memudahkan para guru dalam meningkatkan kemampuan mereka dalam mempelajari tes soal-soal kosakata (vocabulary). Tetapi kendala yang lain adalah para guru belum terbiasa memanfaatkan media busuu online ini. Untuk itu tim abdimas akan mencoba melakukan pelatihan guna meningkatkan kemampuan kompentensi para guru SD tersebut melalui mediai Busuu terhadap kemampuan kosakata (vocabulary) dan berbicara (speaking).

\section{METODE}

Metode yang digunakan dalam melakukan kegiatan pelaksanaan adalah: 1.). Survei/observasi (pengamatan) mendalam. Dalam metode ini untuk mendapatkan data (informasi) tentang permasalahan yang ada di masyarakat, 2.) Konseling yakni membantu menggali permasalahan yang dimiliki oleh masyarakat dan membuka alternative alternatif solusi, dan 3.) dengan melakukan pengajaran secara langsng metode Busuu kepada para guru SD

\section{HASIL DAN PEMBAHASAN}

\subsection{Hasil}

Kegiatan Pengabdian Pada Masyarakatini dilaksanakan dalam bentuk sosialisasi dan pelatihan terprogram, seperti yang ditunjukkan pada tabel berikut: 
Table 1. Rincian Kegiatan

\begin{tabular}{|l|l|}
\hline Pertemuan & Rincian Kegiatan \\
\hline \multirow{5}{*}{$1-3$} & Sosialisasi program \\
\cline { 2 - 3 } & $\begin{array}{l}\text { Materi, diskusi dan tanya jawab seputar pembelajaran } \\
\text { bahasa Inggris dan media pendukung pembelajaran } \\
\text { bahasa Inggris. }\end{array}$ \\
\cline { 2 - 2 } & $\begin{array}{l}\text { Penggalian konsep-konsep tentang media pembelajaran } \\
\text { bahasa Inggris yang kreatif dan inovatif. }\end{array}$ \\
\cline { 2 - 2 } & $\begin{array}{l}\text { Pelatihan pemanfaatan media Busuu Online yang } \\
\text { dibimbing langsung oleh pemateri. }\end{array}$ \\
\hline & $\begin{array}{l}\text { Praktek mengerjkaan soal-soal Kosataka (vocabulary) } \\
\text { bahasa Inggris. }\end{array}$ \\
\cline { 2 - 2 } & Evaluasi program yang dilakukan diakhir kegiatan \\
\hline
\end{tabular}

Sumber: Data Abdimas (2021)

Aktivitas - aktivitas yang terjadi pada pelatihan peningkatan kompetensi guru melalui pemanfaatan media Busuu Online terhadap kemampuan Kosataka (vocabulary) dan berbicara (speaking) bahasa Inggris. pemanfaatan media Busuu Online dalam pembelajaran bahasa Inggris adalah sebagai berikut:

Pada tahap awal kegiatan, peserta dikenalkan pada teori, konsep, dan tujuan pembelajaran bahasa Inggris dan kosakata bahasa Inggris, setelah itu diberikan pengertian mengenai konsep berbagai media yang dapat mendukung kegiatan pembelajaran bahasa Inggris. Lalu setelah mereka siap untuk mendapatkan materi mengenai media pembelajaran, kami selaku pemateri menyajikan slide materi mengenai penjelasan media Busuu Online. Peserta menyimak dengan serius dan membaca secara seksama materi yang sudah diberikan sebelumnya.

Setelah menjelaskan definisi dan teori teori mengenai pemanfaatan media Busuu Online dalam pembelajaran bahasa Inggris, Tim abdimas mulai menjelaskan kegunaan dan langkah-langkah pemanfaatan media Busuu Online.

Pada sesi praktek, setiap peserta membuka laptop masing-masing. Hal pertama yang mereka lakukan adalah mengetik http://totemfieldstoryboards.org/ selaku website penyedia online Bussu di search engine. Setelah website terbuka di laptop masing masing peserta dapat langsung memilih tema Busuu dan belajar kosakata dari beberapa tema yang dibuka.

Berikut ini adalah contoh tabel sesi tanya jawab seputarpemanfaatanmedia Busuu Online dari para Guru di atas:

Tabel 2. Tabel Daftar pertanyaan peserta pelatihan

\begin{tabular}{|c|l|l|l|l|}
\hline No & $\begin{array}{l}\text { Nama } \\
\text { Penanya } \\
\text { (Guru) }\end{array}$ & $\begin{array}{l}\text { Guru Matpel } \\
\text { (Mata pelajaran) }\end{array}$ & Pertanyaan & \multicolumn{1}{|c|}{ Jawaban } \\
\hline 1 & Sri Winarni & $\begin{array}{l}\text { Bahasa Inggris } \\
\text { Kelas 5 }\end{array}$ & $\begin{array}{l}\text { Apa saja yang } \\
\text { harus } \\
\text { dipersiapkan } \\
\text { sebelum } \\
\text { mengunakan } \\
\text { media Busuu } \\
\text { Online? }\end{array}$ & $\begin{array}{l}\text { Yang harus disiapkan saat } \\
\text { mengunakan media Busuu Online } \\
\text { adalah mengetik } \\
\text { http://totemfieldbusuu.org/ selaku } \\
\text { website penyedia online Busuu di } \\
\text { search engine (google search } \\
\text { engine). Setelah website terbuka di } \\
\text { laptop masing - masing peserta } \\
\text { dapat langsung memilih tema } \\
\text { Busuu dan belajar kosakata dari } \\
\text { beberapa tema yang dibuka. }\end{array}$ \\
\hline
\end{tabular}




\begin{tabular}{|c|l|l|l|l|}
\hline No & $\begin{array}{l}\text { Nama } \\
\text { Penanya } \\
\text { (Guru) }\end{array}$ & $\begin{array}{l}\text { Guru Matpel } \\
\text { (Mata pelajaran) }\end{array}$ & Pertanyaan & \multicolumn{1}{|c|}{ Jawaban } \\
\hline 2 & Rita Sandra & $\begin{array}{l}\text { Bahasa Inggris } \\
\text { Kelas 4 }\end{array}$ & $\begin{array}{l}\text { Apakah media } \\
\text { Busuu Online } \\
\text { dapat } \\
\text { dijadikan } \\
\text { media } \\
\text { pendukung } \\
\text { pembelajaran } \\
\text { bahasa } \\
\text { Inggris yang } \\
\text { efektif? }\end{array}$ & $\begin{array}{l}\text { Busuu Online dapat dijadikan } \\
\text { salah satu media pendukung yang } \\
\text { efektif dalam pembelajaran bahasa } \\
\text { Inggris karena dapat melatih } \\
\text { ketrampilan berbahasa Inggris, } \\
\text { khususnya dalam penguasaan } \\
\text { kosakata. }\end{array}$ \\
\hline 3 & Maryanah & $\begin{array}{l}\text { Bahasa Inggris } \\
\text { Kelas 6 }\end{array}$ & $\begin{array}{l}\text { Apa saja } \\
\text { kegunaan dan } \\
\text { fungsi media } \\
\text { Busuu Online } \\
\text { dalam } \\
\text { pembelajaran } \\
\text { bahasa } \\
\text { Inggris? }\end{array}$ & $\begin{array}{l}\text { Kegunaan media Busuu Online } \\
\text { adalah mendukung pembelajaran } \\
\text { bahasa Inggris tidak hanya di } \\
\text { dalam kelas tapi juga di luar kelas. } \\
\text { Fungsi media Busuu Online adalah } \\
\text { salah satu variasi pembelajaran } \\
\text { yang dapat digunakan untuk } \\
\text { meningkatkan kemampuan } \\
\text { kosakata dan ketrampilan bahasa } \\
\text { Inggris. }\end{array}$ \\
\hline
\end{tabular}

Sumber: Data Abdimas (2021)

Tabel 3. Hasil Pre-test guru-guru SD Yasporbi JakartaScore

\begin{tabular}{|c|l|c|}
\hline No & \multicolumn{1}{|c|}{ Nama } & Pre-Test \\
\hline 1 & ANI LESTARI & 70 \\
\hline 2 & DARTA SASMITA & 70 \\
\hline 3 & ASEP ARIS SUSANTO & 73 \\
\hline 4 & SRI WINARNI & 76 \\
\hline 5 & RITA SANDRA & 78 \\
\hline 6 & AGUS HAMID & 76 \\
\hline 7 & RIZKY AGUSETIAWAN & 80 \\
\hline 8 & MARYANAH & 73 \\
\hline 9 & ENTONG SUPRIADI & 70 \\
\hline 10 & ETI MARNI & 75 \\
\hline
\end{tabular}

Sumber: Data Abdimas (2021)

Tabel 4. Score hasil Post-test guru-guru SD Yasporbi Jakarta

\begin{tabular}{|c|l|c|}
\hline NNo & \multicolumn{1}{|c|}{ Nama } & Pre-Test \\
\hline 1 & ANI LESTARI & 75 \\
\hline 2 & DARTA SASMITA & 78 \\
\hline 3 & ASEP ARIS SUSANTO & 80 \\
\hline 4 & SRI WINARNI & 83 \\
\hline 5 & RITA SANDRA & 85 \\
\hline 6 & AGUS HAMID & 80 \\
\hline 7 & RIZKY AGUSETIAWAN & 87 \\
\hline 8 & MARYANAH & 80 \\
\hline 9 & ENTONG SUPRIADI & 78 \\
\hline 10 & ETI MARNI & 80 \\
\hline
\end{tabular}

Sumber: Data Abdimas (2021) 
Tabel 5. Perbandingan score hasil pre-test dan post-test guru-guru SD Yasporbi Jakarta

\begin{tabular}{|c|l|c|c|}
\hline No & \multicolumn{1}{|c|}{ Nama } & Pre-Test & Post-Test \\
\hline 1 & ANI LESTARI & 70 & 75 \\
\hline 2 & DARTA SASMITA & 70 & 78 \\
\hline 3 & ASEP ARIS SUSANTO & 73 & 80 \\
\hline 4 & SRI WINARNI & 76 & 83 \\
\hline 5 & RITA SANDRA & 78 & 85 \\
\hline 6 & AGUS HAMID & 76 & 80 \\
\hline 7 & RIZKY AGUSETIAWAN & 80 & 87 \\
\hline 8 & MARYANAH & 73 & 78 \\
\hline 9 & ENTONG SUPRIADI & 70 & 80 \\
\hline 10 & ETI MARNI & 75 & 80 \\
\hline
\end{tabular}

Sumber: Data Abdimas (2021)

Hasil dari kegiatan pelatihan peningkatan kompetensi guru dengan memanfaatkan media Busuu online terhadap kemampuan kosakata (vocabulary) dan berbicara (speaking) bahasa Inggris adalah peserta pelatihan yang merupakan guru-guru SD Yasporbi Jakarta dapat memahami konsep media pembelajaran dan fungsi media sebagai alat bantu peningkatan ketrampilan berbahasa, khusus nya penggunaan media Busuu online yang dapat membantu guru dalam meningkatkan penguasaan kosakata (vocabulary) dan berbicara (speaking) bahasa Inggris.

\section{Luaran}

Luaran yang akan dihasilkan adalah guru - guru dapat memanfaatkan media Busuu online dan dapat mengerjakan soal - soal kosakata (vocabulary) dan berbicara (speaking) bahasa Inggris yang nantinya terlihat dari perbandingan nilai pre - test dan post- test para guru dan selanjutnya hasil kegiatan ini akan dipublikasikan dalam jurnal.

\section{KESIMPULAN}

Untuk dapat memahami konsep-konsep pembelajaran bahasa inggris melalui media pembelajaran Busuu online, para peserta mengikuti kegiatan pelatihan dengan tertib dan sangat antusias dengan topik tentang peningkatan kompetensi guru melalui media Busuu online terhadap penguasaan kosakata (vocabulary) dan berbicara (speaking)bahasa Inggris.

Hasil pengamatan berdasarkan yang dilakukan pada awal kegiatan, secara umummengindikasikan bahwa pembelajaran bahasa Inggris di Sekolah Dasar (SD) berfokus pada pengenalan kata, pelafalan dan berbicara, membaca, tata bahasa, dan menulis teks sederhana. Teknik dan media yang digunakan dapat disesuaikan dengan kondisi lingkungan sekolah. Sebagian besar peserta belum terbiasa dengan bahasa Inggris oleh karena nya bahasa Inggris hanya dis isipkan percakapan sederhanadan pengenalan kata. Beberapa peserta mengeluhkan pengucapan bahasa Inggris yang perlu latihan terlebih dahulu sebelum mengajarkan kepada siswa.

Secara umum program pengabdian pada masyarakat yang berjudul Pemanfaatan Media Busuu Online untuk meningkatkan kompetensi guru bahasa Inggris SD terhadap kemampuan kosakata (Vocabulary) dan berbicara (speaking) berlangsung dengan baik dan menurut para peserta pelatihankegiatan ini sangat bermanfaat dan membentu mereka dalam pengajaran dan pengenalan bahasa Inggris. Menurut kepala sekolah SD Yasporbi Jakarta dalam sambutannya diakhir kegiatan mengatakan bahwa kegiatan pengabdian 
seperti ini sangat mereka perlukan dan sangat bermanfaat bagi mereka dan sekiranya memungkinkan mereka meminta agar di tahuntahun yang akan datang pengabdian seperti ini dapat lagi dilaksanakan di sekolah tersebut. Selain itu, Para guru juga merasakan banyak manfaat dari kegiatan ini.

Dari hasil evaluasi terhadap peningkatan kompetensi guru media pembelajaran Busuu online terhadap penguasaan kosakata bahasa Inggris, yang peserta lakukan di akhir kegitan terlihat bahwa para guru sudah mulai paham dan bisa meningkatkan penguasaan kosakata dan ketrampilan berbahasa Inggris dengan media pembelajaran Busuu online walaupun dari segi teknis mereka belum terbiasa dengan pemanfaatan teknologi untuk meningkatkan kompetensi guru.

\section{DAFTAR PUSTAKA}

Barber, Charles. 2000. The English Language: A Historical Introduction. Cambridge University Press. Departemen Pendidikan Nasional. 1998. Pedoman Pelatihan Profesional Guru Sekolah Dasar. Jakarta: Depdiknas.

Freeborn, Dennis. 2006. From Old English to Standard English: A Course Book in Language Variations Across Time (Studies in English Language). New York: Macmillan.

Harmer, Jeremy. 2007. The Practice of English Language Teaching. :Pearson Education Limited.

Richard, J.C and Renandya, W.A. 2002. Methodology in Language Teaching: An Antology of Currant

\section{InterNet} Practice. Cambridge University Press.

http://www.davidprasetyo.com/2015/11/pengertian-storyboard.html

http://totemfieldstoryboards.org/

http://accad.osu.edu/womenandtech/Storyboard\%20Resource/ 